Journal of Animal and Veterinary Advances 10 (8): 972-979, 2011

ISSN: $1680-5593$

(C) Medwell Journals, 2011

\title{
Isolation and Identification of Bucella melitensis in Goats
}

\author{
Maged Ahmed AL-Garadi, S. Khairani-Bejo, Z. Zunita and A.R. Omar \\ Department of Veterinary Pathology and Microbiology, \\ Faculty of Veterinary Medicine, University Putra Malaysia, \\ 43400 Serdang, Selangor, Malaysia
}

\begin{abstract}
Isolation of Brucella melitensis is the standard gold of identification and confirmation of animal brucellosis. However in Malaysia, Brucella sp., infection of goat was increasing recently and there is no evidence for diagnosis of the serover of Brucella sp., that cause the disease in goat population except the detection of serological methods. Isolation and identification of Brucella melitensis have been done by bacteriological methods in addition to conventional Polymerase Chain Reaction (PCR) and Real-time PCR for detection of Brucella melitensis from samples collected from vaginal swabs on suspected farm. In conclusion, four isolate have been got out of 300 vaginal samples and all isolate is belong to Brucella melitensis server 1 . The Real-time PCR is the easy and save method for confirmation of brucellosis in goats population.
\end{abstract}

Key words: Goat, Brucellosis, isolation, Real-time PCR, PCR, goats

\section{INTRODUCTION}

The most reliable and the only unique method for diagnosing animal brucellosis is isolation of Brucella species (Alton et al., 1988). A definite diagnosis requires the isolation of Brucella sp. from blood, bone marrow or other tissues. However, cultural examinations are time-consuming, hazardous and not sensitive. Thus, clinicians often rely on the indirect proof of infection (Al-Dahouk et al., 2003; Bounaadja et al., 2009).

The bacteriological diagnosis of Brucella melitensis can be made by microscopic examination of stained smears from vaginal swabs, placentas or aborted foetuses (Stamp's method). However, morphologically related organisms such as Brucella ovis, Chlamydophila abortus or Coxiella burnetii can cause misleading diagnoses. Therefore, isolation of $B$. melitensis on appropriate culture media is recommended for accurate diagnosis (Garin-Bastuji et al., 2006). Thus, taking vaginal swabs and milk samples is the best way to isolate of $B$. melitensis from sheep and goats. The spleen and lymph nodes (iliac, supramammary and prefemoral) are the best sites for obtaining samples for isolation of Brucella melitensis during post-mortem examination (Marin et al., 1996).

Recently, the Polymerase Chain Reaction (PCR) were shown to be a valuable method for detecting DNA from different fastidious and non-cultivable agents (Brikenmeyer and Mushahwar, 1991). Although, there are several studies on Brucella-DNA detection by PCR from pure culture (Fekete et al., 1990; Herman and Herman, 1992), there is no substantial evidence to indicate the presence of brucellosis in goats in Malaysia but then there were no studies being done on the diagnosis of brucellosis in these small ruminants in the past years and there has been no report of strong serological reactor or the presence of $B$. melitensis in goats in Malaysia until 2007 (Bahaman and Bejo, 2007). Except annual Department of Veterinary medicine (DVS) report for brucellosis eradication programs and Bahaman et al. (2009) were reported infection of goats with Brucella melitensis by In house Rose Bengal Plate Test (RBPT) and other serological test.

Diagnosis of brucellosis is vital for early situation of proper therapy as untreated cases may progress to chronic stage. Though, the demonstration of the causative agent in blood is considered as the most conclusive test in the diagnosis of brucellosis, isolation of Brucella organism by blood culture is relatively low (Jain and Tilak, 2008).

The diagnosis of brucellosis is based on a detailed history obtained from the patients and the isolation of Brucella sp. from blood cultures are accepted as the standard method. The definitive diagnosis of brucellosis requires isolation of the bacterium from blood, bone marrow or tissue samples. Although, the sensitivity of blood culture method varies depending on the individual laboratory practices, quantity of bacteria in blood and the methods used, it changes between 15-70\%. Bone marrow

Corresponding Author: Maged A. Al-Garadi, Department of Veterinary Pathology and Microbiology,

Faculty of Veterinary Medicine, University Putra Malaysia, 43400 Serdang, Selangor, Malaysia 
culture is considered as the gold standard for the diagnosis of brucellosis since, the relatively high concentration of Brucella in reticuloendothelial system enables the detection of the organism (Aliskan, 2008).

\section{MATERIALS AND METHODS}

Vaginal swabs samples: About 300 vaginal swab samples were collected from goats and transported in Brucella broth as transport media.

Bacterial isolation: The vaginal swabs were cultured on Brucella agar with Brucella supplement (Pronadisa $(B)$ ) then it was incubated in $37^{\circ} \mathrm{C}$ for 5 days. The plates were examined after 3 days and then it was observed in each day to observe the development of the bacterial colonies. Brucella sp. were identified by morphological, cultural and biochemical characteristics such as oxidase, urease, $\mathrm{CO}_{2}$ requirement, $\mathrm{H}_{2} \mathrm{~S}$ production, nitrate reduction, growth in the presence and absence of thionin and basic fuscine $\left(20 \mathrm{ug} \mathrm{mL} \mathrm{mL}^{-1}\right)$.

Serotyping: All Brucella melitensis local isolate which got from this study have been sub-cultured and lyophilized by lymphilizer and sent to serotyping under biohazard safety condition shipmen. Typing was kindly performed by Veterinary Laboratories Agency (VLA-UK) by standard procedures. Lyophilized pure culture of four isolates were sent to the Brucella Reference Research Statutory and Exotic Bacterial Department, Veterinary Laboratory Agency, New Haw, Addlestone, Surry, United Kingdom for typing to biovar level.

\section{Identification of Brucella melitensis isolates DNA extraction from samples}

Biochemical test: Phenotyping of Brucella melitensis is the most reliable technique to diagnosis of Brucella sp. Bacterial ability to grow in media containing thionin $\left(20 \mu \mathrm{g} \mathrm{mL}^{-1}\right)$ and basic fuchsin $\left(20 \mu \mathrm{g} \mathrm{mL}^{-1}\right)$ was done. Growth in Tripl Sugar Iron (TSI) agar test, oxidase, Urease activity test, nitrate reduction and $\mathrm{CO}_{2}$ requirement was carried out on the suspected colony to identify local isolate (Jang et al., 2004 ; Nielsen and Duncan, 1990).

\section{Conventional Polymerase Chain Reaction (PCR)}

DNA extraction: The DNA was extracted from bacterial culture using Promega kit (Promega, USA). Briefly, $1 \mathrm{~mL}$ overnight Brucella culture was transferred to an eppendorf tube. Samples were centrifuged at $16,000 \times \mathrm{g}$ for 2 min to pellet the cells. The supernatant was removed and $600 \mu \mathrm{L}$ of nucleilysis solution was added. The cells were re-suspended by gently pipeting. The samples were incubated at $80^{\circ} \mathrm{C}$ for $5 \mathrm{~min}$ to lyse the cells; then it was cooled to room temperature. About $3 \mu \mathrm{L}$ of RNase solution was added to the cell lysate. The tube was inverted 2-5 times to mix. The sample was incubated at $37^{\circ} \mathrm{C}$ for $15-60 \mathrm{~min}$. The sample was cooled to room temperature. About $200 \mu \mathrm{L}$ of protein precipitation solution was added to the RNase-treated cell lysate. The sample was vortexed vigorously at high speed for $20 \mathrm{sec}$ to mix the protein precipitation solution with the cell lysate. The sample was incubated on ice for $5 \mathrm{~min}$ and it was centrifuged at $16,000 \times \mathrm{g}$ for $3 \mathrm{~min}$. The supernatant containing the DNA was transferred to a clean $1.5 \mathrm{~mL}$ microcentrifuge tube containing $600 \mu \mathrm{L}$ isopropanol. The sample was mixed gently by inversion until the thread-like strands of DNA form a visible mass. Sample was centrifuged at $16,000 \times \mathrm{g}$ for $2 \mathrm{~min}$ then the supernatant was poured off carefully and the tube was drained on clean absorbent study. About $600 \mu \mathrm{L}$ of room temperature $70 \%$ ethanol was added and the tube was inverted gently several times to wash the DNA pellet. The sample was centrifuged at $16,000 \times \mathrm{g}$ for $2 \mathrm{~min}$. The ethanol was aspirated carefully. The tube was drained on clean absorbent study and the pellet allowed to air-dry for $10-15 \mathrm{~min} .100 \mu \mathrm{L}$ of DNA rehydration solution was added to the tube. The DNA was rehydrated by incubating the solution overnight at $4^{\circ} \mathrm{C}$. The purity and concentration was measured.

Conventional PCR protocol: A $1 \mathrm{~mL}$ overnight culture was transferred into sterile cups and DNA was extracted according to the manufacturer's protocol with a Wizard genome purification kit (Promega, USA) for gram negative bacteria as previous. The upstream primer that is derived from the $3^{\prime}$ end of the genetic element IS711. Whereas, the downstream primer was derived from signature sequences of Brucella melitensis P1 (5'-CATGCGCTATGT CTGGTTAC-3') and P2 (5'-AGTGTTTCGGCTCAGAA TAATC-3') were used to amplify a 252 bp fragment (Redkar et al., 2001). For DNA amplification, $24 \mu \mathrm{L}$ of reaction mixture was added to $1 \mu \mathrm{L}$ of purified DNA. The master mixture for the PCR included the following: $1 \mathrm{x}$ buffer, $1.5 \mathrm{mM} \mathrm{MgCl}_{2}, 200 \mu \mathrm{M}$ each deoxynucleoside Triphosphate (dNTP) (Qiagen, Germany), $25 \mu \mathrm{M}$ each primer and $2 \mathrm{U}$ of Taq DNA polymerase (Qiagen, Germany). PCR amplifications were performed with a Bio-rad temperature cycler (Mycylcer Bio-Rad California, USA). The primary PCR amplification consisted of an initial denaturation step at $95^{\circ} \mathrm{C}$ for $5 \mathrm{~min} ; 34$ cycles at $95^{\circ} \mathrm{C}$ for $1.15 \mathrm{~min}, 45^{\circ} \mathrm{C}$ for $2 \mathrm{~min}$ and $72^{\circ} \mathrm{C}$ for $2 \mathrm{~min}$ and $\mathrm{a}$ final elongation phase at $72^{\circ} \mathrm{C}$ for $5 \mathrm{~min}$. After the $1 \mathrm{st}$ reaction, $1 \mu \mathrm{L}$ of the amplified product was added to $24 \mu \mathrm{L}$ of the master mixture. Each time a PCR was 
performed, a positive control (Brucella melitensis $16 \mathrm{M}$ references strain DNA was ran and a reagent control (all PCR reagents without DNA) to evaluate the success of amplification and the purity of the reagents, respectively. The product of the PCR was electrophoresed with $1 \mu \mathrm{L}$ of gel loading buffer (concentrated) through a $2 \%$ agarose gel at $75 \mathrm{~V}$ for $1.30 \mathrm{~h}$ in $1 \times \mathrm{TBE}$ buffer (Mbiotech, Korea). Molecular size markers 100 bp (Promega, Madison, Wis.) were run concurrently. The gel stained with ethidium bromide $\left(0.5 \mu \mathrm{g} \mathrm{mL}{ }^{-1}\right)$ was examined under UV light for the presence of a 252 bp band and photographed by Bio-rad Gel doc. system for documentation and determination of expected band.

Detection of Brucella melitensis by Real-time-PCR: All local isolate and reference strain was subjected into Real-time PCR using a specific primers for Brucella melitensis for detection IS711 gene to established the rapid technique for diagnosis and confirmation of Brucella melitensis local isolate. The primers P1 (5'-CATGCGCTATGT CTGGTTAC-3') and P2 (5'-AGTGTTTCGGCTCAGAATAATC-3') were used to amplify a 252 bp fragment (Redkar et al., 2001). Real-time PCR was performed on DNA extracted from bacterial culture.

Two microliters of the DNA suspensions were used in the Real-time PCR reactions. About $0.5 \mu \mathrm{L}(0.5 \mu \mathrm{M})$ from each the forward primer and reverse primer which have previously been described (Redkar et al., 2001). About $12.5 \mu \mathrm{m}$ SYBRR green master mixes was used (Qiagen, Germany) and 9.5 $\mu \mathrm{L}$ RNAse free water to give a final volume of $25 \mu \mathrm{L}$. Amplification was carried out on the opticon Real-time PCR detection system (Biorad, USA), PCR parameters consisted of a single 5 min incubation step at $95^{\circ} \mathrm{C}$ followed by a 30 sec step at $658^{\circ} \mathrm{C}$ and by 34 cycles consisting of $30 \mathrm{sec}$ at $65^{\circ} \mathrm{C}, 15 \mathrm{sec}$ at $95^{\circ} \mathrm{C}$ and $30 \mathrm{sec}$ at $65^{\circ} \mathrm{C}$.

To confirm that the amplification signals were the result of specific target amplification, the real-time amplification was followed by melt curve analysis (from $60-95^{\circ} \mathrm{C}$ in $20 \mathrm{~min}$ with increments of $0.5^{\circ} \mathrm{C}$ ). Non-template controls (NTC, consisting of $\mathrm{H}_{2} \mathrm{O}$ ) were used as negative controls for amplification.

Characterization of Brucella melitensis isolates: Brucella sp. is differentiable by Polymerase Chain Reaction (PCR) and phenotyping procedure (Gandara et al., 2001; Meikle et al., 1989).

Negative staining: Negative staining is a rapid technique to differentiate between Brucella melitensis and
$Y$. enterocolitica by shape and cell morphology. The sample have been mixed with negative stain by equal portion on a parafilm sheet and the samples was applied to the grids and the excess was removed by touching a filter study to the edge of the grid after draying for 15-30 min the grid can be examined as usual by electron microscopy (Bozzola and Russell, 1999).

Cell morphology was examined using a Philips electron microscopy with cells grown for 2 days at $37^{\circ} \mathrm{C}$ on standard nutrient agar. Negative staining (with 1\% uranyl acetate) was performed.

Sequencing IS711 region of Brucella melitensis isolates: The IS711 gene was amplified from five isolates of Brucella melitensis and Brucella melitensis $16 \mathrm{M}$ reference strain after cultivation of Brucella sp. at $37^{\circ} \mathrm{C}$ for $48 \mathrm{~h}$.

DNA have been extracted by DNA extraction kit (Promega, USA) and amplified by using conventional PCR protocol as previously described. PCR product was separated by electrophoresis system and the gene was present on predicted size.

The gels were cut by sharp blades in specific fragment size and re-purified the gene product from the gel by using Promega DNA purification system (Promega, USA). The re-purified product have been checked for purity and integrity by using agarose electrophoresis methods to confirm the re-purification.

The samples were sent for sequencing and the BLASTN query result of genes amplified for local Brucella melitensis isolates were compared with gene sequences of IS711 obtained from GenBank under accession number (ref/NC 003317.1) for IS711 region and Brucella melitensis $16 \mathrm{M}$ reference strain.

\section{RESULTS AND DISCUSSION}

Bacterial isolation: A total of four isolates were obtained from 300 vaginal samples and the Veterinary Laboratories Agency (VLA)-UK confirmed isolates were Brucella melitensis biotype 1 .

Identification of Brucella melitensis isolates: The local isolates were appeared the ability to grow on media containing $20 \mu \mathrm{L}$ basic fuchsin but no on thionin media, the confirmation includes biochemical, dye tolerance was showing in Table 1.

All Brucella strains were identified as Brucella melitensis by biochemical characteristics such as positive oxidase and Urease, negative $\mathrm{H}_{2} \mathrm{~S}$, no $\mathrm{Co}_{2}$ requirement and growth in the present of basic fuchsin and thionin (20 $\mathrm{mg} \mathrm{mL}^{-1}$ ). 
Polymerase Chain Reaction (PCR): The conventional PCR is highly specific and all Brucella strains were identified as B. melitensis by conventional PCR which successfully amplified 252 bp by specific shown as in Fig. 1.

Detection of Brucella melitensis by Real time-PCR: The results indicated that IS711 Real-time PCR assay is a specific and sensitive tool for detection of Brucella sp. infections in goats.

The successful Real-time PCR has been achieved with high efficiency with CT value mean $12.8 \pm 0.8$ as shown in Fig. 2. The melting temperature curve indicates

Table 1: Showed the biochemical test results and dye tolerate for the four Brucella melitensis local isolate from vaginal swabs

\begin{tabular}{|c|c|c|}
\hline \multicolumn{2}{|l|}{ Staining/biochemical test } & B. melitensis \\
\hline Modified ziehl-neelsen stain & & Acid fast, red coccobacilli \\
\hline Growth in triple sugar iron & & + \\
\hline $\mathrm{CO}_{2}$ requirement & \multicolumn{2}{|r|}{-} \\
\hline $\mathrm{H}_{2} \mathrm{~S}$ & \multicolumn{2}{|r|}{-} \\
\hline Oxidase & \multicolumn{2}{|r|}{+} \\
\hline Nitrate reduction & \multicolumn{2}{|r|}{+} \\
\hline Urease & \multicolumn{2}{|r|}{+} \\
\hline Growth on basic fuschin tolerate & \multicolumn{2}{|r|}{+} \\
\hline Thionin tolerate & \multicolumn{2}{|r|}{-} \\
\hline \multicolumn{3}{|c|}{$\begin{array}{l}\text { Real-time PCR result from Brucella melitensis local isolate and } \\
\text { Brucella melitensis } 16 \mathrm{M} \text { reference strain showing CT and Tm } \\
\text { value }\end{array}$} \\
\hline Description & $\mathrm{C}(\mathrm{t})$ & $\mathrm{Tm}$ \\
\hline Positive control & 12.29 & 82.5 \\
\hline 1 & 13.38 & 82.0 \\
\hline 2 & 12.27 & 82.0 \\
\hline 3 & 13.91 & 82.0 \\
\hline 4 & 12.16 & 82.0 \\
\hline Non template control & $\mathrm{N} / \mathrm{A}$ & 74.5 \\
\hline
\end{tabular}

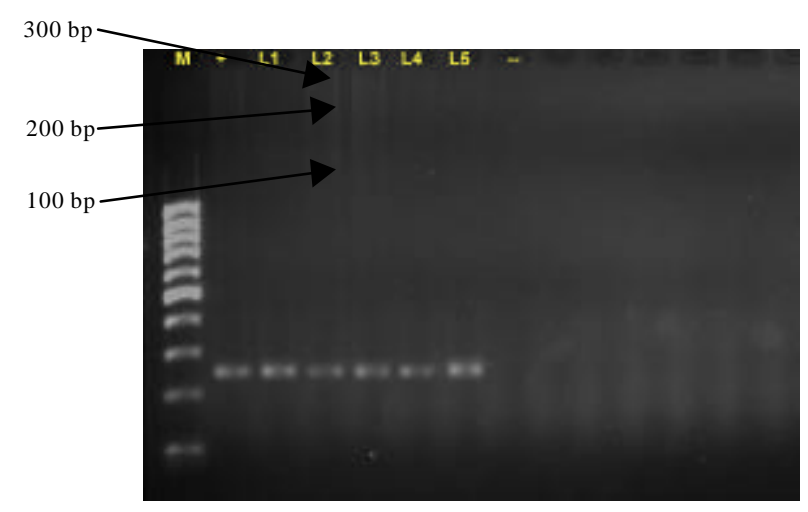

Fig. 1: Show the expected band of Brucella melitensis from local isolate. Lane $\mathrm{M}$ is $100 \mathrm{bp}$ marker, lane + Brucella melitensis $16 \mathrm{M}$ reference strain as a positive control, lane L1-L4 local isolate from goats farm in current study. Lane L5 local isolate from sheep in previous study Lane was negative control there is no noisy curved on the specific melting temperature which it is around 82 as shown in Fig. 3 and Table 2.

\section{Characterization of Brucella melitensis isolates}

Negative staining: Coccobacili or sporadically formed short rods arranged individually or in irregular clusters. The cell shape, morphology and diameter are similar to Brucella melitensis $16 \mathrm{M}$ reference strain as in Fig. 4 and clearly distinguished from Brucella abortus and Yersinia enteroloytica 0:9 reference strains Fig. 5 .

\section{Sequencing of IS711 region of Brucella melitensis} isolates: The analyzed gene sequences showed high percent similarity when compare to the GenBank database.

The amplification products for all isolate were consistent with the predicted size as in Fig. 6 and 7. Phylogenetic tree and sequencing blast result were

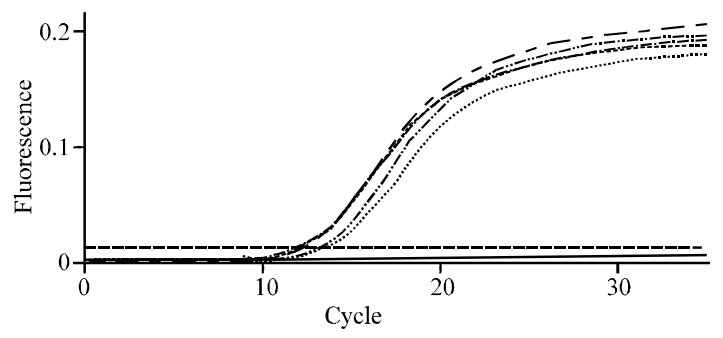

Fig. 2: Successful PCR amplification curve of all Brucella melitensis local isolate from 1-4 and Brucella melitensis $16 \mathrm{M}$ reference strain which are up the threshold line (---) and non template control under the serrated line which indicated there is no amplification occurred

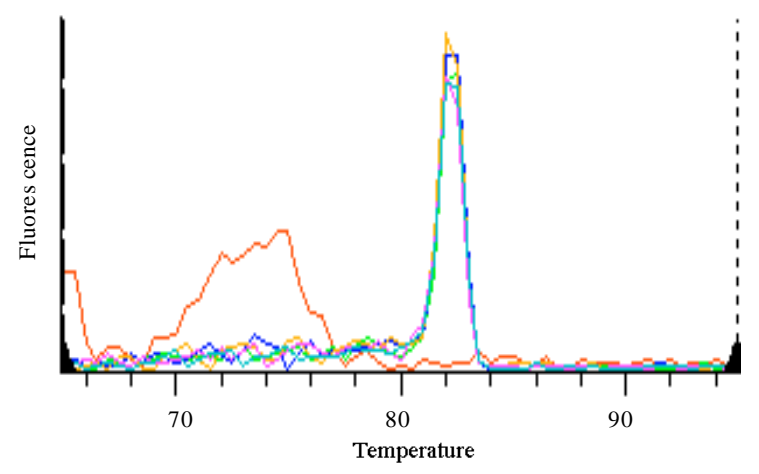

Fig. 3: Melting curve graph showing the melting temperature of all local isolate and Brucella melitensis $16 \mathrm{M}$ reference strain with mean of $82 \pm 0.5$ 


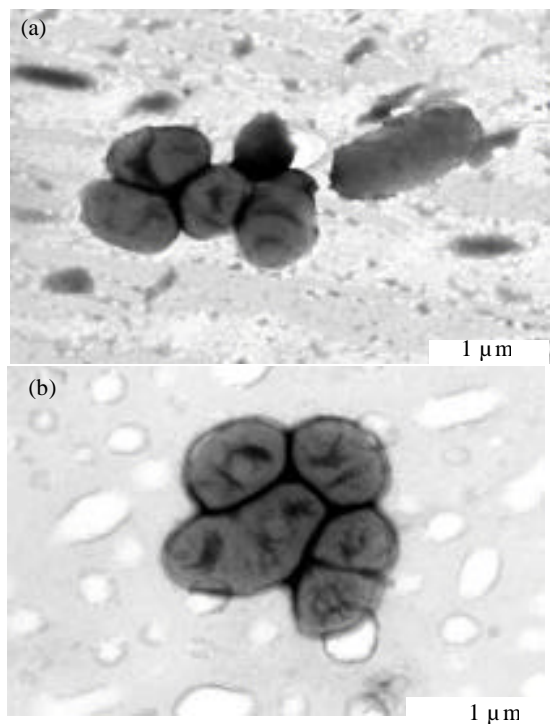

Fig. 4: Transmission electron microscopy of the Brucella melitensis local strain (a-21.5 K) stained with negative staining shows an organism with undistinguished morphology from Brucella melitensis $16 \mathrm{M}$ reference strain (b-27.5 K)
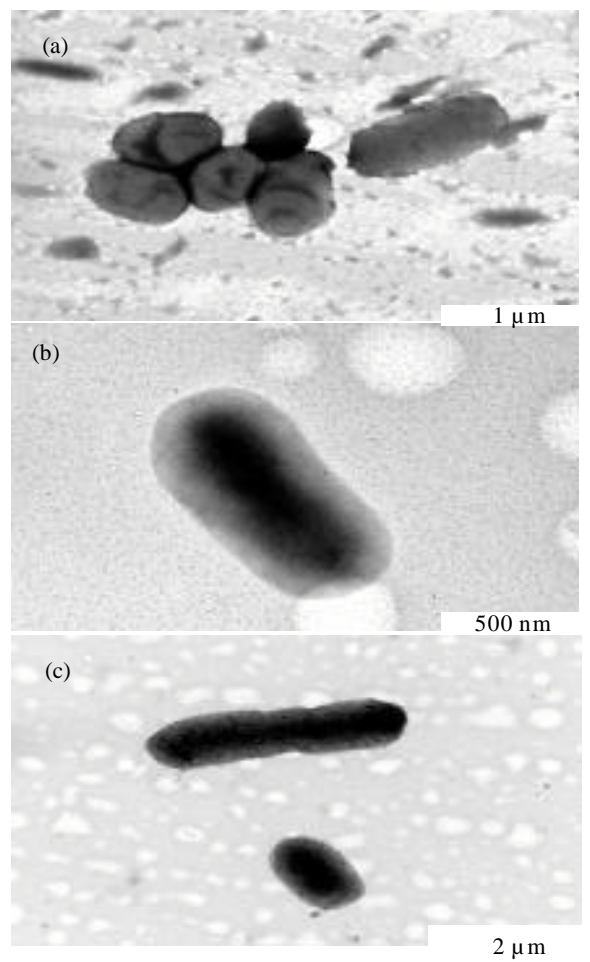

Fig. 5: Transmission electron microscopy of the Brucella melitensis local strain (a-21.5 K) isolate after negative staining shows an organism with distinguished morphology from Brucella abortus (b-46 K) and Yersinia enterolytica reference strain (c-12.5 K)

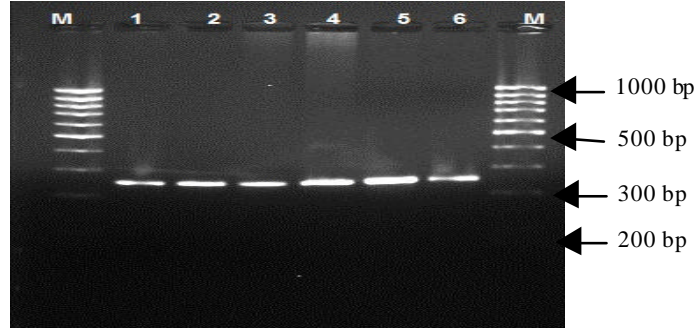

Fig. 6: PCR Product after re-purification IS711 region from agarose gel with expected band (252 bp) of Brucella melitensis $16 \mathrm{M}$ reference strain (1), 4611 Brucella melitensis local isolate (2), Brucella melitensis local isolate (3), Brucella melitensis local isolate (4). Brucella melitensis local isolate (5) and $(\mathrm{M})$ is $100 \mathrm{bp}$ DNA marker

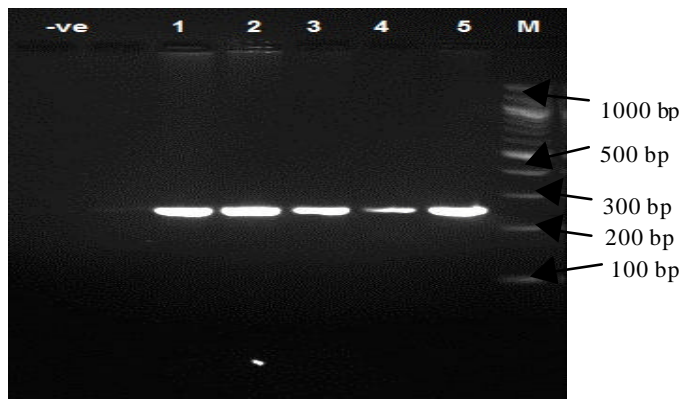

Fig. 7: Successful PCR product with expected band (252 bp) after amplification IS711 region of Brucella melitensis $16 \mathrm{M}$ reference strain $(1,6)$, 4611 Brucella melitensis local isolate (2), Brucella melitensis local isolate (3), Brucella melitensis local isolate (4). Brucella melitensis local isolate (5) and (M) is 100 bp DNA marker

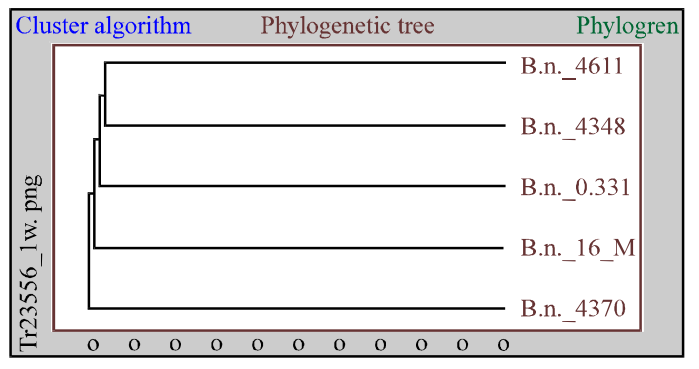

Fig. 8: Phylogenetic tree of the amplified (252 bp) sequences from IS711 region in Brucella species. The local isolate, Brucella melitensis is most closely related to Brucella melitensis $16 \mathrm{M}$ comparing with GeneBank data and enrolled reference from Brucella melitensis $16 \mathrm{M}$ showing all reference have $100 \%$ similarity in 252 bp of IS711 with Brucella melitensis 
showed in Fig 8-10, subsequently. Isolation of Brucella sp. is usually difficult, hazards, time consuming and unpractical, however the isolation of Brucella sp. is considered to be the only unequivocal method for the confirmation (Alton et al., 1988).

The Serological test is the most suitable screening methods for goat's brucellosis whilst isolation of the organisms is important to confirm the disease. It is sometimes important to analyse, multiple isolates within a given species to determine whether they represent a single strain or multiple strains. If a species of bacteria is isolated and cultivated in the laboratory, it is known as a strain. A single isolate with distinctive characteristic may also represent a strain. These typing methods are useful

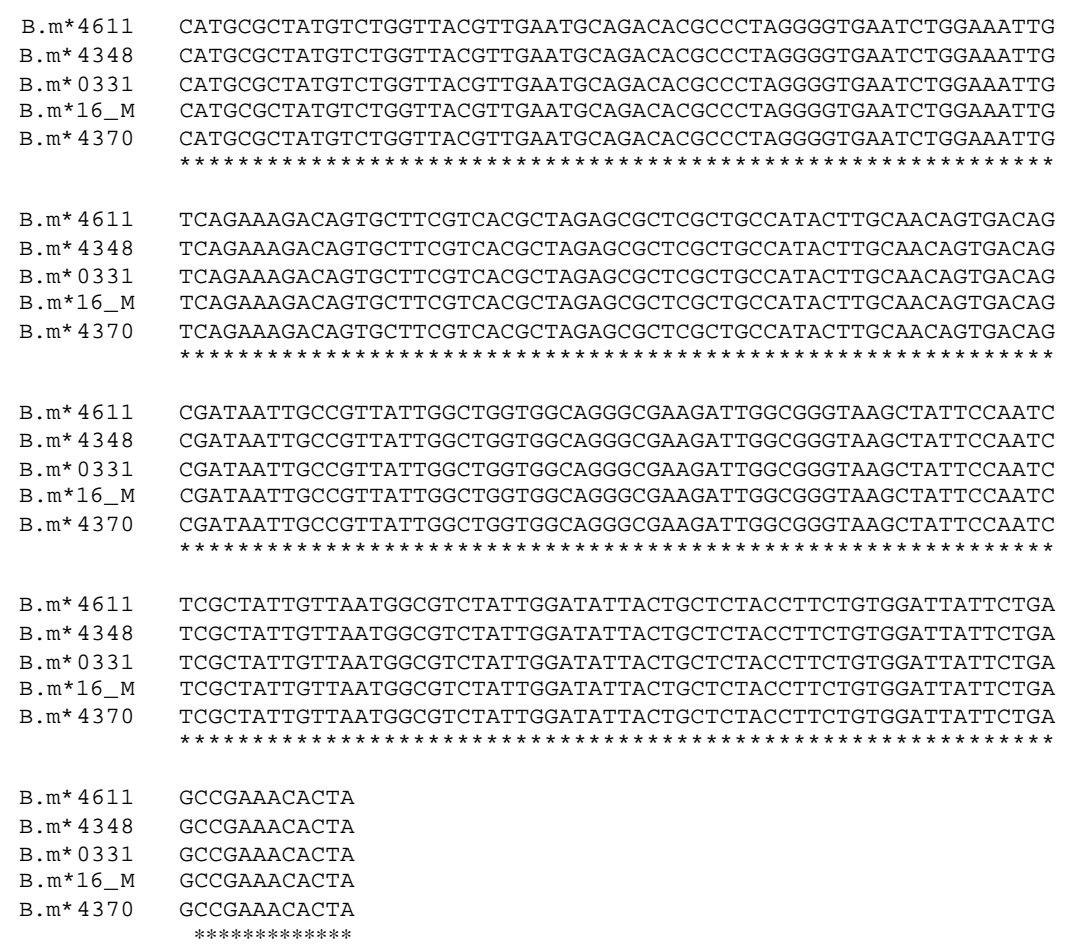

Fig. 9: Multiple sequence alignment of Brucella melitensis local isolates show $100 \%$ homology in all four isolate nucleotides (5'-3') rather than with Brucella melitensis $16 \mathrm{M}$ reference strain (B.m.*) Brucella melitensis

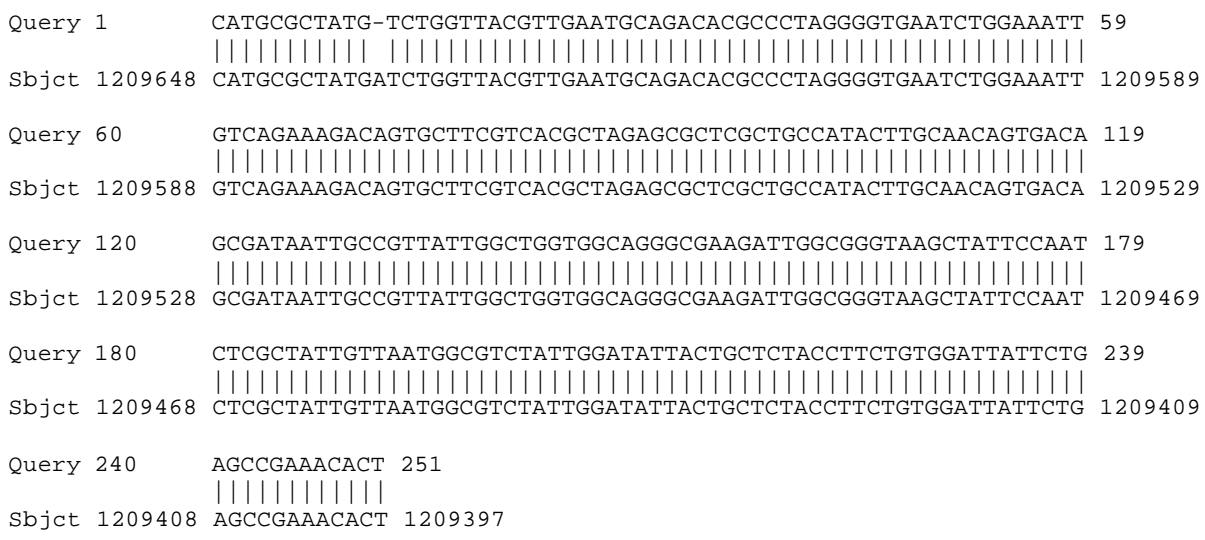

Fig. 10: Blast result of Brucella melitensis sequence of 252 bp from IS711 region in hypothetical protein gene (5' -3') with Brucella melitensis $16 \mathrm{M}$ chromosome I, complete sequence (ref|NC_003317.1|) showed 99\% homology with this part. The gap is $1 / 252$ from primer designation 
for infection control in hospital, epidemiological studies and understanding the pathogenesis of infection. Collection of vaginal sample is the easiest methods for sampling, however it is not usually reflected the true prevalence of the herd's infection. There are many factors conflicting isolation of Brucella melitensis in goats by vaginal samples which is including the stage of the diseases, time of abortion, excretion of Brucella in vaginal exudates or uterine exudates and the stage of the infection rather than the quantity of Brucella in the samples. Teixeria-Gomes et al. (2000) and Leyla et al. (2003) isolated Brucella melitensis from vaginal samples and aborted foetuses in sheep and goats and the result of this study in isolation of Brucella melitensis organisms from vaginal swabs from goats is consistent with the reports of these researchers.

Four Brucella melitensis isolates were isolated from vaginal samples. The isolates were able to grow on media containing $20 \mu \mathrm{L}$ basic fuchsin but disable to grow in the present of thionin in the media. All biochemical test results were match with references strains except thionin result which match with identification made by Corbel (1991). Many Brucella melitensis isolated in India, Italy, Kuwait, Saudi Arabia, the Federal Republic of Germany and Zimbabwe were inhibited by thionin (20 micrograms $\mathrm{mL}^{-1}$ ) but not by basic fuchsin (20 micrograms $\mathrm{mL}$ ).

It has often been reported that the sensitivity of culture method is often low depending on the diseases stage, Brucella species, culture medium, quantity of circulating bacteria and culture techniques employed (Marin et al., 1996; Gamazo et al., 1993). Phenotypic techniques, those that detect characteristics expressed by the microorganism and genotypic techniques, those that involve direct DNA-based analysis of chromosomal or extrachromosomal genetic elements. The conventional PCR need more time and hardly and hazard chemical was used (e.g., ethidium bromide) for staining the gel comparing with real-time one but it was use also here to establish the protocol for using IS711 Real-time PCR moreover to confirm, it is doubt result. For this reason, researchers propose the employment of IS711 Real-time PCR as a complementary tool in brucellosis screening programs and for confirmation of diagnosis in doubtful cases to establish the new biomarker.

The negative staining technique is quite simple, rapid and requires minimum of experience and equipment. Generation of a negative stained grid takes $<4 \mathrm{~min}$ and even to provide a rapid clinical diagnosis with certain infection by indication of the present of bacteria. A good negative stain revealed the outline and form of structure that are spread out on a support film. The detection of
Brucella melitensis and differentiated it according to its morphological shape and size in a specific case history of abortion and characteristic clinical signs can be useful to confirmation of the infection by Brucella melitensis and is useful methods to differentiated it from other infection specially $Y$. enterolytic. Brucella melitensis is non motile bacteria and does not have flagella as in the figures of negative staining.

The mobile genetic element IS711 has proven a useful target for molecular characterisation based on the number and distribution of IS711 copies within the bacterial genomes. Sequencing data confirm that the actual size of the IS711 amplification products matched the predicted size of $252 \mathrm{bp}$. The sequencing of the amplified fragments for the IS711 gene from four isolates showed 100\% homology. The PCR-sequencing based analysis of gene IS711 showed 100\% homology to Brucella melitensis $16 \mathrm{M}$ genome.

This 252 bp fragment was found to be present in all of the Brucella melitensis isolate tested. The IS711 fragment was showed $99 \%$ homology to (ref|NC_003317.1) Brucella melitensis $16 \mathrm{M}$ complete sequence in gene bank. The $1 \%$ contrast was shown from original primer designated by Redkar et al. (2001).

From sequencing analysis result, there is no mutation point in all isolate. The genetic homology and diversity between the local isolates itself and with reference strain would be established an idea to make good planning for control the disease and compare it with gene bank data to see the relative of that's local isolate with other global records especially with related with Malaysia goats exporting countries such as Thailand which have boarding with Malaysia, especially it is very close to the sampling place.

\section{CONCLUSION}

In this study, Brucella melitensis serovar 1 is the corresponding of brucellosis in goats brucellosis in Malaysia which have severity in transmission of brucellosis to human been. The national measures for controlling need to improve the diagnostic programme in order to assess the control and spread of brucellosis. The eradication programme is should be consider the technique that can be detected the Brucella melitensis in low prevalence area to eradicated the brucellosis such as Real-time PCR.

\section{ACKNOWLEDGEMENT}

This research was funded by the Government of Malaysia through the RUGS Fund (Grant no. 91120). 


\section{REFERENCES}

Al-Dahouk, S., H. Tomaso, K. Nockler, H. Neubauer and D. Frangoulidis, 2003. Laboratory-based diagnosis of brucellosis: A review of the literature. Part II: Serological tests for brucellosis. Clin. Lab., 49: 577-589.

Aliskan, H., 2008. The value of culture and serological methods in the diagnosis of human brucellosis. Mikrobiyol. Bull., 42: 185-195.

Alton, G.G., L.M. Jones, R.D. Angus and J.M. Verger., 1988. Techniques for the brucellosis laboratory. Vet. Res. Commun., 13: 420-420.

Bahaman, A.R. and S.K. Bejo, 2007. Areview of the epidemiology and control of brucellosis in malaysia. J. Vet. Malaysia, 19: 1-6.

Bahaman, A.R., O. Shahaza, S. Khairani-Bejo and Z. Zunita, 2009. In-house rose bengal plate agglutination test (RBPT) for a rapid diagnosis of brucellosis in goats in Malaysia. Int. J. Trop. Med., 4: $116-118$.

Bounaadja, L., D. Albert, B. Chenais, S. Henault, M.S. Zygmunt, S. Poliak and B. Garin-Bastuji, 2009. Real-time PCR for identification of Brucella spp.: A comparative study of IS711, bcsp31 and per target genes. Vet. Microbiol., 137: 156-164.

Bozzola, J.J. and L.D. Russell, 1999. Electron Microscopy: Principles and Techniques for Biologists. 2nd Edn., Jones and Bartlett Publishers, Massachusetts, pp: 634.

Brikenmeyer, L.G. and I.K. Mushahwar, 1991. DNA probe amplification methods. J. Virol. Meth., 35: 117-126.

Corbel, M.J., 1991. Identification of dye-sensitive straine of Brucella melitensis. J. Clin Microbiol., 29: 1066-1068.

Fekete, A., J.A. Bantle, S.M. Halling and M.R. Sanborn, 1990. Preliminary development of diagnostic test for Brucella using PCR. J. Applied Bacteriol., 69: 216-227.
Gamazo, C., A.I. Vitas, I. Lopez-Goni, R. Diaz and I. Moryion, 1993. Factors affecting detection of Brucella melitensis by BACTEC NR730, a nonradiometric system for hemocultures. J. Clin. Microbiol., 31: 3200-3203.

Gandara, B., A.L. Merino, M.A. Rogel and E. MartinezRomero, 2001. Limited genetic diversity of Brucella spp. J. Clin. Microbiol., 39: 235-240.

Garin-Bastuji, B., J.M. Blasco, C. Marin and D. Albert, 2006. The diagnosis of brucellosis in sheep and goats, old and new tools. Small Ruminant Res., 62: 63-70.

Herman, L. and D. Herman, 1992. Identification of Brucella sp. by using the polymerase chain reaction. Applied Environ. Microbiol., 58: 2099-2101.

Jain, R. and V. Tilak, 2008. Evaluation of different serological techniques in laboratory diagnosis of brucellosis. J. Indian Med. Assoc., 106: 522-524.

Jang, S.S., E.L. Biberstein and D.C. Hirsh, 2004. A Diagnostic Manual of Veterinary Clinical Bacteriology and Mycology. University of California, Davis.

Leyla, G., G. Kadri and O. Umran, 2003. Comparison of ploymerase chaine reaction and bacteriological culture for the diagnosis of sheep brucellsosis using aborted fetus samples. Vet. Microbiol., 93: 53-61.

Marin, C.M., M.P. Jimenez- Bagues, M. Barberan and J.M. Blasco, 1996. Comparison of two selective media for the isolation of Brucella melitensis from naturally infected sheep and goats. Vet. Rec., 138: 409-411.

Meikle, P.J., M.B. Perry, J.W. Cherwonogrodzky and D.R. Bundle, 1989. Fine structure of a and $\mathrm{m}$ antigens from Brucella biovars. Infect. Immun., 57: 2820-2828.

Nielsen, K. and J.R. Duncan, 1990. Animal Brucellosis. 1st Edn., CRC Press, Boca Raton, pp: 464.

Redkar, R., S. Rose, B.J. Bricker and V.D. Vecchio, 2001. Real-time detection of Brucella abortus, Brucella melitensis and Brucella suis. Mol. Cell Probes, 15: 43-52.

Teixeria-Gomes, A.P., A. Cloeckaert and M.S. Zygmunt, 2000. Characterization of heat, oxidative and acid strees responses in Brucella melitensis. Infect. Immun., 68: 2954-2961. 